\title{
Intrauterine Osteogenesis Imperfecta in Four Siblings
}

\author{
S. CHAWLA,* M.B., B.S., D.M.R.
}

Brit. med. F., 1964, 1, 99-101

Osteogenesis imperfecta is a rare condition characterized by fragility of the bones, leading to multiple fractures. Malebranche (1684) first described the disease in a 20 -year-old man. Lobstein (1835) named it "osteopsathyrosis idiopathica." Vrolik (1849), describing the condition for the first time in a newborn infant with numerous intrauterine fractures of the long bones and a poorly ossified calvarium, called it osteogenesis imperfecta. Looser (1906) proposed the terms "osteogenesis imperfecta congenita" and "osteogenesis imperfecta tarda" to distinguish the early and late forms of the disease.

Osteogenesis imperfecta tarda is hereditary, but the congenital variety is often found in children of parents who have no sign of the disease. Seedorff (1949), reporting on 180 affected members of 55 Danish families, found seven cases of the congenital type ; in six of these both parents were normal.

Heys, Blattner, and Robinson (1960) emphasized the association of osteogenesis imperfecta and odontogenesis imperfecta in 18 families studied by them. There were only two cases of the congenital form in this series.

The true incidence of the congenital form of the disease is not known. Potter (1952) gave it as 1 in over 60,000 deliveries at the Chicago Lying-in Hospital ; Gain and Lawson (1952) encountered 1 case in 7,951 deliveries including stillbirths at the Memorial Hospital at Phoenix ; and Posner and Goldman (1957) reported one case at the Bronx Hospital in a total of 40,000 deliveries conducted during a 20-year period.

Freda, Vosburgh, and Di Liberti (1961), in a comprehensive review of the world literature, could find only 90 cases of this condition, to which they added 16 of their own, bringing the total number of reported cases to 106. Sarma (1960) encountered one case among 543 abnormal babies.

The disease is associated with defective formation and differentiation of subperiosteal and endosteal bone. Diminished osteoblastic activity has been considered the probable causal mechanism (Ruth, 1943 ; Caffey, 1961). Follis (1952) described the disease as a connective-tissue diathesis. According to Potter (1952) the principal disturbance seems to be in the excessive destruction of bone trabeculae already formed.

The diagnosis is usually made clinically in the newborn infant and is confirmed radiologically. Intrauterine diagnosis on prenatal films of the maternal abdomen were made by Danelius (1933), Frerking and Zink (1952), Aitken, Cohen, and Verco (1954), Posner and Goldman (1957), Black (1958), and Jonas (1959). Since prenatal films are not obtained on pregnant women as a routine, the intrauterine diagnosis can be made only if there is abnormal presentation or some other indication for radiological examination.

\section{Family History}

The parents were married in 1952. The mother, aged 28 , has one sister alive and well. The father, aged 33 , has five brothers and one sister, all alive and well. The first child, a female, was born in 1954 and is in good health.

Case 1.-A second full-term female child, weighing $5 \mathrm{lb} .2 \mathrm{oz}$. $(2,325 \mathrm{~g}$.$) , was born in a maternity centre in 1956$. It was noticed

\footnotetext{
- Professor of Radiology, Lady Hardinge Medical College and Hospital, New

by the attending midwife and the parents that the baby had many deformities of the extremities and the ribs. She was brought to hospital next day. On examination the head was found to be large and soft, and one had the sensation of holding a bag of bones. Sclerae were not blue, there were multiple deformities of all the extremities, and crepitus was evident at the sites of recent fractures. Heart and lungs were normal. A diagnosis of osteogenesis imperfecta congenita was made from clinical as well as radiological examination. At 3 years of age the child died of intractable respiratory infection after developing multiple fractures during this period.

The third child, a female, was born in 1957, after a full-term normal pregnancy. She is alive and has no congenital abnormality.

Case 2.- The fourth child, a male, was born in 1958 at a maternity centre, with multiple deformities of the limbs. He was brought to hospital when 3 days old. On examination he was fairly well nourished, weighing $6 \mathrm{lb}$. $(2,720 \mathrm{~g}$.). There were multiple angulations of the upper and lower limbs and beading of the ribs, and the skull was soft, pliable, and parchment-like. The sclerae were not blue; no other abnormality was found. Radiographs of the skeleton revealed changes of osteogenesis imperfecta (Fig. 1). This child died at home nine months later.

The fifth child, a female, was born in 1959 after a full-term normal pregnancy. She has no congenital abnormality.

Case 3.-The sixth child, a male, was born in 1960 at the same maternity centre. According to the parents he had multiple deformities of the extremities and a soft pliable head, and died 24 hours later. This child was not examined by any physician.

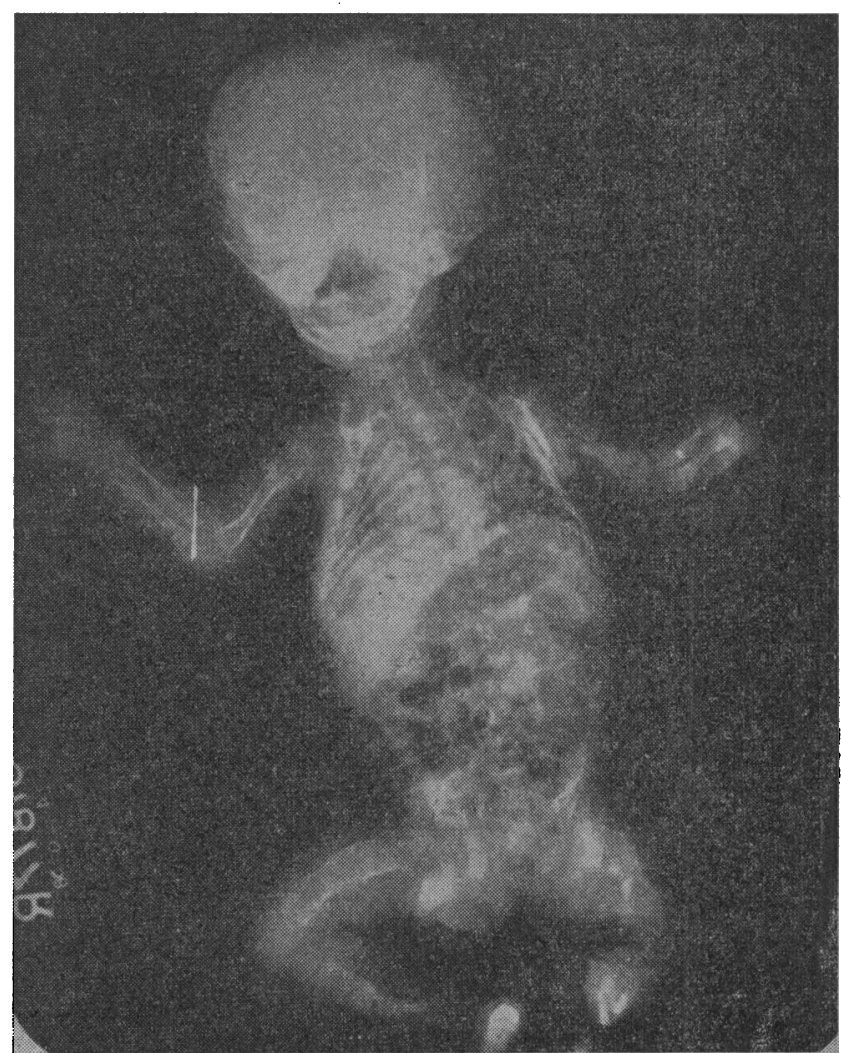

FIG. 1.-Case 2. Radiograph showing numerous fractures, marked deformities of the long bones, and callus formation at the fracture sites. There is incomplete ossification of the calvarium with multiple Wormian bones and large number of healing fractures in the ribs with callus formation. 
Case 4.-The seventh child, a male, was born at home on 28 March 1962. Similar deformities were noted by the parents, and the infant was brought to hospital the next day. On examination he weighed $4 \mathrm{lb} .10 \mathrm{oz}$. $(2,100 \mathrm{~g}$.) ; the sclerae were not blue. There were multiple angulations and deformities of the limbs, with a soft skull. Radiographs revealed typical changes of osteogenesis imperfecta (Figs. 2 and 3). The infant was discharged three weeks later, on 21 April. He died at home on 13 July, presumably of multiple fractures and respiratory infection.

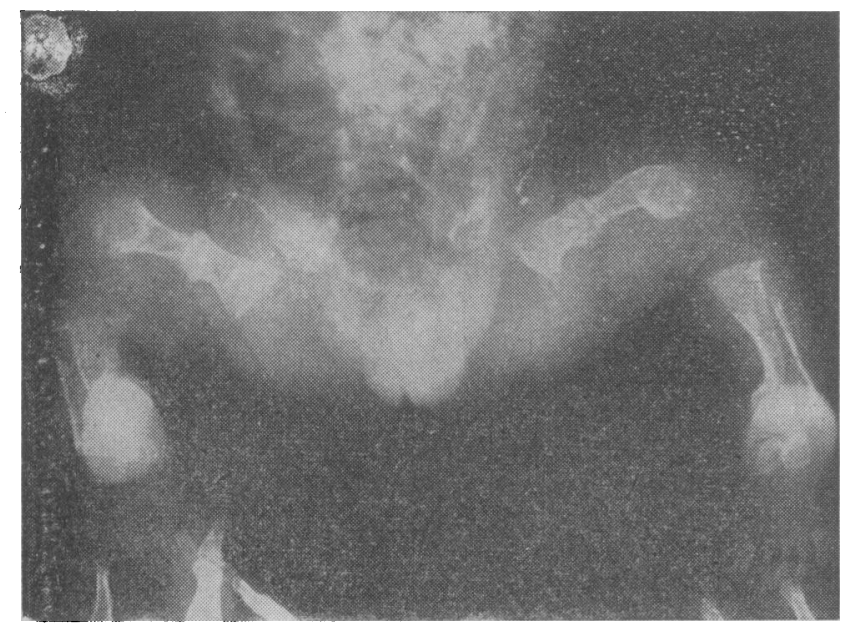

FLG. 2.-Case 4. Radiograph of pelvis and lower limbs, showing bllateral symmetrical fractures with excess callus formation in midfemoral shafts. There are multiple fractures in both tibia and left fibula.

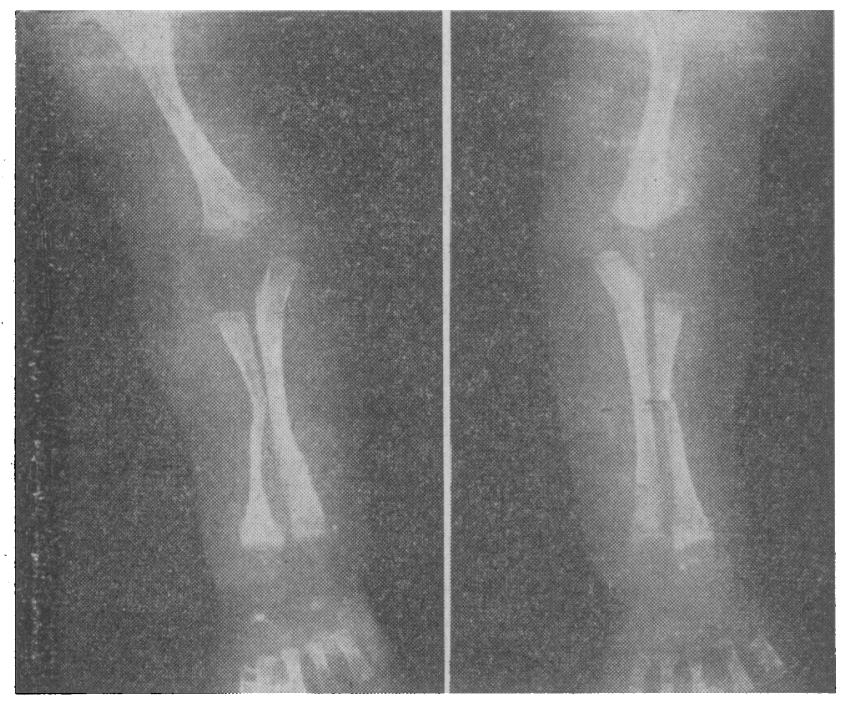

FIG. 3.-Case 4. Radiograph of upper arms, showing slender long bones with thin cortices and flaring at the ends. There are many cystic areas and multiple fractures in all the bones.

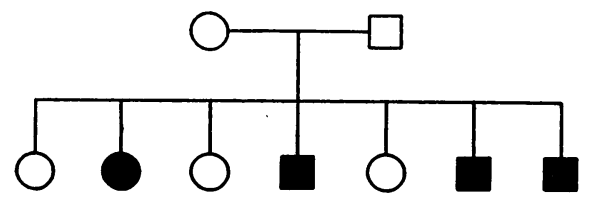

FIG. 4.-Genealogical tree, showing normal and abnormal siblings.

\section{Radiological Features of Osteogenesis Imperfecta Congenita}

The essential radiological features are hypoplasia and thinning of the cortex, with a scanty spongiosa. The long bones have slender shafts that widen abruptly near the epiphyses. Occasionally the shaft may have a cystic appearance. The skull shows incomplete mineralization of the bones, of membranous origin, and mosaic rarefaction is often seen in the occipital area, due to numerous Wormian bones. The vertebrae are usually biconcave and the disks protrude into the vertebral bodies. Fractures occur in all the bones, but are particularly apt to occur in the ribs and femora. These heal easily with good callus formation.

\section{Discussion}

The hereditary aspects of oesteogenesis imperfecta congenita are usually not considered important, whereas in the infantile and tarda type the disease definitely follows a dominant Mendelian trait. Blue sclerae, frequent fractures, and deafness occur in that order of frequency in the affected families of the infantile and late types, as a definite hereditary factor seen through several generations. Because of the early death of most infants with the congenital type of osteogenesis imperfecta, heredity does not usually play an impressive part. The possibility that the variety present in the newborn may be inherited through recessive genes has been considered but never proved (Potter, 1952).

According to Freda et al. (1961) in the case of normal parents - that is, without brittle bones and blue sclerae-who have one infant affected with osteogenesis imperfecta congenita, the possibility of giving birth to a second affected child is almost negligible. Several other authors (Jonas, 1959 ; Heys et al., 1960) have emphasized that the congenital type is usually not inherited.

Goldfarb and Ford (1954) described osteogenesis imperfecta congenita in two consecutive female siblings of the same parents; the first child was normal. The second and third siblings were born with multiple deformities of the limbs and ribs. The infants had blue sclerae and soft skulls.

Adatia (1957) also described osteogenesis imperfecta congenita in two consecutive siblings. The first and second children of these parents were normal. No reference could be found in the literature of more than two siblings being similarly affected. Usually the infants do not live beyond 18 months (Freda et al., 1961); in this family, however, the first affected child lived three years.

There is no evidence of similar affection in the parents or their relations. The three living female children show no evidence of blue sclerae or odontogenesis imperfecta. There is no history of consanguinity. The disease is said to be more frequent in males. In the family in question three males and one female were affected, three female siblings being normal.

In view of the involvement of four siblings of the same parents, the popular current view that osteogenesis imperfecta congenita is usually not inherited may have to be modified, but further investigations into the familial incidence of this disease are required before definite conclusions can be reached. Chromosomal study of the family is contemplated.

\section{Summary}

Osteogenesis imperfecta 'congenita in four siblings is described. Because of the involvement of four siblings of the same parents, the view that the condition is usually not inherited may have to be modified.

I am grateful to Dr. Bery, lecturer, and Dr. (Miss) K. J. Indra, registrar, Department of Radiology, for their helpful suggestions in the preparation of this paper.

\section{REFERENCES}

Adatia, M. D. (1957). 7. Indian med. Prof., 4, 1810.

Aitken, G. W. E., Cohen, A., and Verco, P. W. (1954). F. Fac. Radiol. (Lond.), 6, 62 .

Black, W. P. (1958). 7. Obstet. Gynaec. Brit. Cwlth, 65, 1005.

Caffey, J. (1961). Pediatric X-ray Diagnosis, 4th ed., p. 910. Year Book Medical Publishers, Chicago.

Danelius, G. (1933). Quoted by Frerking and Zink (1952). 
Follis, R. H., jun. (1952). F. Pediat., 41, 713.

Freda, V. J., Vosburgh, G. J., and Di Liberti, C. (1961). Obstet. and Gynec., $18,535$.

Frerking, H. W., and Zink, O. C. (1952). Amer. F. Roentgenol., 67, 103. Gain, D. D., and Lawson, D. E. (1952). Radiology, 58, 221.

Goldfarb, A. A., and Ford, D. (1954). 7. Pediat., 44, 264.

Heys, F. M., Blattner, R. J., and Robinson, H. B. G. (1960). Ibid., 56, 234.

Jonas, W. (1959). 广. Obstet. Gynaec. Brit. Cwlth, 66, 485.

L.obstein, J. F. (1835). Quoted by Freda et al. (1961).
Looser, E. (1906). Quoted by Posner and Goldman (1957).

Malebranche (1684). Quoted by Freda et al. (1961).

Posner, A. C., and Goldman, J. A. (1957). Amer. F. Obstet. Gynec., 73, 1143.

Potter, E. L. (1952). Pathology of the Fetus and the Newborn, p. 449. Year Book Publishers, Chicago.

Ruth, E. B. (1943). Arch. Path., 36, 211.

Sarma, V. (1960). Brit. med. F., 2, 1856.

Seedorff, K. S. (1949). Quoted by Freda et al. (1961).

Vrolik, W. (1849). Quoted by Freda et al. (1961).

\title{
ABO Blood Groups and Staphylococcal Infection
}

\author{
A. J. ZUCKERMAN,* M.B., M.SC.; D. L. MILLER,* M.B.; J. C. MCDONALD,* M.D.
}

Brit. med. F., 1964, 1, 101

The presence of blood-group-like substances in bacteria was first noted in shigellae and pneumococci by Eisler $(1930,1931)$; they have since been demonstrated in several species (Springer et al., 1961). Illchmann-Christ and Nagel (1954) found that anti- $\mathrm{A}$ antibody was removed from $\mathrm{O}$ and $\mathrm{B}$ sera by staphylococci and postulated that staphylococci possessed an A-like receptor. If this were so, persons belonging to blood-group A might carry staphylococci in the nose more frequently than those of other groups or have an increased susceptibility to staphylococcal infections, owing to an inability to produce anti-A antibody. This hypothesis was not supported by Coulter's (1962) finding of a significant excess of blood group O in nasal carriers and in women with a history of staphylococcal infection in a maternity hospital in Australia. White and Shooter (1962) found a slight but not significant group $O$ excess among nasal carriers and patients with wound sepsis in male surgical patients in a London hospital.

As the result of a comprehensive survey made in 1959-60 of staphylococcal nasal carriage and infection in Royal Air Force recruits we also had the opportunity to examine this question. The field and laboratory methods used in the survey have been described (Miller et al., 1962). The recruits' ABO and rhesus blood group and place of birth were obtained from their medical records. The blood group and the result of at least one nasal swab examination were available for 2,226 recruits born within the British Isles; second swabs had been examined from 1,466 of these men.

To serve as a control Dr. A. C. Kopéc, of the Nuffield Blood Group Centre, kindly supplied an analysis of the distribution of blood groups for a sample of 47,108 R.A.F. recruits tested by the service during 1956-61. The study population and controls were divided into three groups according to their place of birth, as described in other studies of blood group and infection (McDonald and Zuckerman, 1962 ; Zuckerman and McDonald, 1963), and the statistical significance of the difference between the observed and expected distributions was tested by the same method (Woolf, 1955).

\section{Results}

The distribution of the $\mathrm{ABO}$ blood groups and rhesus factor in the 2,226 recruits was analysed in six main groups (Table I). The observed percentages of carriers and non-carriers in each ABO blood group, making due allowance for the regional constitution of the observed groups, showed no significant

\footnotetext{
- From the Epidemiological Research Laboratory, Central Public Health Laboratory, Colindale, London.
}

differences from the expected proportions calculated from the control figures. This was equally true in all geographical regions. The proportion of $\mathrm{Rh}$-negative recruits in each geographical region showed only minor variations. Among the 133 men who experienced a septic lesion during the period of observation there was a small excess of persons in blood-group A (Table II), but this was not significant.

We conclude that there is no association between ABO blood group and susceptibility to staphylococcal nasal carriage or infection.

TABLE I.-Observed (O) and Expected (E) Blood-group Distributions in Relation to the Nasal Carriage of Staphylococcus aureus

\begin{tabular}{|c|c|c|c|c|c|c|c|c|c|}
\hline \multirow{2}{*}{$\begin{array}{l}\text { Staphylococcal } \\
\text { Carrier State }\end{array}$} & \multirow{2}{*}{$\begin{array}{l}\text { No. of } \\
\text { Men }\end{array}$} & \multicolumn{2}{|c|}{ Group $\mathrm{O}$} & \multicolumn{2}{|c|}{ Group A } & \multicolumn{2}{|c|}{ Group B } & \multicolumn{2}{|c|}{ Group AB } \\
\hline & & (\%) & $\underset{(\%)}{\mathrm{E}}$ & (\%) & $\underset{(\%)}{E}$ & (\%) & $\underset{(\%)}{\mathrm{E}}$ & (\%) & $\begin{array}{c}\mathbf{E} \\
(\%)\end{array}$ \\
\hline All carriers on first swab & 988 & $47 \cdot 4$ & $46 \cdot 5$ & $42 \cdot 7$ & $41 \cdot 7$ & $7 \cdot 4$ & $8 \cdot 8$ & 2.5 & $3 \cdot 0$ \\
\hline $\begin{array}{l}\text { swab } \\
\text { Carriers }\end{array}$ & $\begin{array}{r}1,238 \\
454\end{array}$ & $\begin{array}{l}44 \cdot 5 \\
46 \cdot 7\end{array}$ & $\begin{array}{l}46 \cdot 4 \\
46 \cdot 5\end{array}$ & $\begin{array}{l}43 \cdot 2 \\
42 \cdot 3\end{array}$ & $\begin{array}{l}41.9 \\
41.6\end{array} \mid$ & $\begin{array}{l}9 \cdot 0 \\
8 \cdot 1\end{array}$ & $\begin{array}{l}8.7 \\
8.8\end{array}$ & $\begin{array}{l}3 \cdot 3 \\
2 \cdot 9\end{array}$ & $\begin{array}{l}3.0 \\
2 \cdot 9\end{array}$ \\
\hline $\begin{array}{l}\text { Non-carriers on both } \\
\text { swabs }\end{array}$ & 669 & $45 \cdot 4$ & $46 \cdot 1$ & $42 \cdot 5$ & $42 \cdot 0$ & $8 \cdot 4$ & $8 \cdot 7$ & $3 \cdot 7$ & $3 \cdot 1$ \\
\hline $\begin{array}{l}\text { First swab positive, } \\
\text { second swab negative }\end{array}$ & 186 & $47 \cdot 3$ & $46 \cdot 2$ & $45 \cdot 2$ & $42 \cdot 3$ & * & & * & \\
\hline second swab positive & 157 & 46.5 & $46 \cdot 5$ & $40 \cdot 1$ & $41 \cdot 4$ & - & & - & \\
\hline
\end{tabular}

* Numbers of men insufficient for analysis.

Note: The detailed figures on which this table is based are available on request.

TABLE II.-Observed and Fxpected Blood-group Distributions in 133

\begin{tabular}{|c|c|c|c|}
\hline & & Observed (\%) & Expected (\%) \\
\hline $\begin{array}{cc}\text { Group } & \text { O } \\
\text { ” } & \text { A } \\
” & \text { B } \\
\text { ” } & \text { AB }\end{array}$ & $\begin{array}{ll}\ldots & \ldots \\
\cdots & \cdots \\
\cdots & \cdots\end{array}$ & $\begin{array}{r}44 \cdot 4 \\
47 \cdot 4 \\
5 \cdot 3 \\
3 \cdot 0\end{array}$ & $\begin{array}{r}45 \cdot 9 \\
42 \cdot 1 \\
8 \cdot 3 \\
3 \cdot 0\end{array}$ \\
\hline
\end{tabular}

We are indebted to Mrs. Judith Munk for her help with the statistical analysis and to the Director-General of the Royal Air Force Medical Services for permission to publish this report.

\section{REFERENCES}

Coulter, J. R. (1962). Nature (Lond.), 195, 301. Eisler, M. (1930). Z. Immun.-Forsch., 67, 38. - (1931). Ibid., 73, 37.

Illchmann-Christ, A., and Nagel, V. (1954). Ibid., 111, 307.

McDonald, J. C., and Zuckerman, A. J. (1962). Brit. med. F., 2, 89.

Miller, D. L., McDonald, J. C., Jevons, M. P., and Williams, R. E. $\mathbf{O}$. (1962). F. Hyg. (Lond.), 60, 451.

Springer, G. F., Williamson, P., and Brandes, W. C. (1961). \}. exp. Med., 113, 1077.

White, H., and Shooter, R. A. (1962). Brit. med. F., 2, 307

Woolf, B. (1955). Ann. hum. Genet., 19, 251.

Zuckerman, A. J., and McDonald, J. C. (1963). Brit. med. F., 2, 537. 